\title{
Analysis of in-situ EXAFS data of supported metal catalysts using the third and fourth cumulant
}

\author{
Eveline Bus $^{a}$, Jeffrey T. Miller ${ }^{b}$, A. Jeremy Kropf ${ }^{c}$, Roel Prins ${ }^{a}$ and Jeroen A. van \\ Bokhoven*,a \\ ${ }^{a}$ Institute for Chemical and Bioengineering, ETH Zurich, 8093 Zurich, Switzerland. Fax: 0041-44-6321162; Tel: 0041-44-6325542; \\ E-mail: j.a.vanbokhoven@chem.ethz.ch \\ ${ }^{b}$ BP Research Center, E-1F, Naperville, IL 60563, USA. \\ ${ }^{c}$ Chemical Engineering Division, Argonne National Laboratory, Argonne, IL 60439, USA.
}

Receipt/Acceptance Data [DO NOT ALTER/DELETE THIS TEXT]

Publication data [DO NOT ALTER/DELETE THIS TEXT]

DOI: 10.1039/b000000x [DO NOT ALTER/DELETE THIS TEXT]

X-ray absorption spectra of supported Pt catalysts with various Pt cluster sizes were collected between 77 and $673 \mathrm{~K}$, in inert and hydrogen atmospheres. When analyzing these spectra with the standard EXAFS equation a Pt-Pt bond contraction and a large increase in the inner potential correction were observed with increasing temperature. These errors are up to $0.08 \AA$ and $10 \mathrm{eV}$ for clusters of $1 \mathrm{~nm}$ in diameter. They were corrected by including the third and fourth cumulants as fit parameters. Fit guidelines were developed to analyze EXAFS data of supported metal catalysts collected at elevated temperatures, allowing for asymmetry and broadening or sharpening of the pair distribution function. These comprise fixing fit parameters, using different $k$-weightings, and identifying trends in series of experiments. By fitting the EXAFS spectra using these guidelines, it was determined that in small Pt clusters the Pt-Pt bond is $0.10 \AA$ shorter than in bulk Pt. These contracted bonds relax to distances near that of bulk Pt upon hydrogen chemisorption. 


\section{Introduction}

X-ray absorption spectroscopy (XAS) is widely used to study supported metal catalysts $^{1,2}$. The extended X-ray absorption fine structure (EXAFS) part of the spectrum contains information on the local structure around the X-ray absorbing atom. ${ }^{3}$ In the single-scattering approximation, the EXAFS function can be written as

$$
\chi(k)=\sum_{j} A_{j}(k) \sin \left(\phi_{j}(k)\right)
$$

where $j$ refers to the $\mathrm{j}^{\text {th }}$ coordination shell, which is a group of atoms of the same type that lie approximately at the same radial distance, and $A \mathrm{j}(k)$ is the amplitude. If the local disorder is small, the path length distribution within a coordination shell can be expressed using a Gaussian function. The amplitude is then approximated by

$$
A_{j}(k)=\frac{N_{j} S_{0}{ }^{2} F_{j}(k)}{k R_{j}^{2}} \exp \left(-2 k^{2} \sigma_{j}{ }^{2}\right) \exp \left(-2 R_{j} / \lambda\right)
$$

where $N_{\mathrm{j}}$ is the coordination number, $S_{0}{ }^{2}$ is the amplitude reduction factor, $F_{\mathrm{j}}(k)$ is the element specific backscattering amplitude, $R_{\mathrm{j}}$ is the average distance between the absorbing atom and the atoms in the $\mathrm{j}^{\text {th }}$ shell, and $\lambda$ is the mean free path of the photoelectron. $\sigma_{\mathrm{j}}^{2}$ is the Debye-Waller factor that quantifies the disorder. It consists of a dynamic term due to the thermal motion of the atoms and a static term due to structural disorder. ${ }^{4}$ The argument of the sine function in eq. (1) is written as

$$
\phi_{j}(k)=2 k R_{j}+\delta_{j}(k)
$$

where $\delta_{\mathrm{j}}$ is the phase shift experienced by the photoelectron in the scattering process. $N$, $R$, and $\Delta \sigma^{2}$ are obtained from analysis of the EXAFS spectra. An inner potential correction, $\Delta E_{0}$, is often included. It is related to the phase shift and allows for 
dissimilarity in $E_{0}$ compared to the reference compound or corrects for a different choice of $E_{0}$ in the reference and the investigated sample.

If the standard EXAFS equation (eqs. (1)-(3)) is used to analyze spectra of systems with large disorder, incorrect values of the varied parameters can be obtained. ${ }^{5}$ At elevated temperatures the atom vibrational amplitude increases, leading to a nonsymmetric, or anharmonic distribution in the instantaneous bond length. ${ }^{4}$ Asymmetry can also be caused by static disorder with a non-Gaussian pair distribution function (PDF). ${ }^{2}$ Due to asymmetry or broadening of the PDF the Debye-Waller factor changes and thus the determination of $N_{\mathrm{j}}$. The phase shift is affected and thus the distance determination. 4,6,7 Equations (2) and (3) are invalid if the PDF is broad or non-Gaussian and have to be adjusted. A commonly used procedure is to describe the distances in a coordination shell by a probability distribution. This leads to

$$
\chi(k)=\sum_{j} \frac{N_{j} S_{0}{ }^{2} F_{j}(k)}{k R_{j}^{2}} \int P\left(r_{j}\right) \frac{\exp \left(-2 r_{j} / \lambda\right)}{k r_{j}^{2}} \sin \left(2 k r_{j}+\delta_{j}(k)\right) \mathrm{d} r_{j}
$$

$P\left(r_{\mathrm{j}}\right) \mathrm{d} r_{\mathrm{j}}$ is the probability of finding the $\mathrm{j}^{\text {th }}$ species in the range $r_{\mathrm{j}}$ to $r_{\mathrm{j}}+\mathrm{d} r_{\mathrm{j}}$. Expanding the terms containing $r_{\mathrm{j}}$ in a Taylor series about $R_{\mathrm{j}}=\left\langle r_{\mathrm{j}}\right\rangle$, the amplitude of the EXAFS function may be written as

$$
\ln \left[\frac{A(k) k R_{j}^{2}}{N S_{0}^{2} F(k)}\right]=C_{0}-\frac{2 R_{j}}{\lambda}-\frac{(2 k)^{2}}{2 !} C_{2}+\frac{(2 k)^{4}}{4 !} C_{4}+\ldots
$$

and the phase may be written as

$$
\phi(k)-\delta(k)=2 k R_{j}-\frac{(2 k)^{3}}{3 !} C_{3}+\frac{(2 k)^{5}}{5 !} C_{5}+\ldots
$$

The coefficients $C_{\mathrm{n}}$ are called cumulants and are a measure of the deviation of the PDF from the Gaussian shape. $4,6,8,9 C_{0}$ is zero if the distribution is normalized. The second 
cumulant is the Debye-Waller factor. The third cumulant $\left(C_{3}\right)$ measures the asymmetry and the fourth cumulant $\left(C_{4}\right)$ the sharpening or broadening of the pair distribution function. ${ }^{10}$ Liquids, ${ }^{9,11}$ molten salts, and alloys ${ }^{8,12}$ in general have a high disorder, thus the anharmonic contributions to the atom vibrations must be taken into account when fitting the EXAFS data. Several studies on solids deal extensively with the anharmonicity of the pair distribution function, $9,13,14$ but only few groups have taken it into account in the analysis of EXAFS spectra of catalysts, 2,7,15-19 although the static disorder in highly dispersed metal clusters on supports and other heterogeneous catalysts is high. ${ }^{2,20,21}$ Other groups recognized the asymmetry in the $\mathrm{PDF}^{22}$ and the resulting errors in the fit parameters 20,21 , but do not correct for it. The structure of the catalyst during reaction is of interest, because it leads to the establishment of structure-activity relationships and the design of stable, active, and selective catalysts. This structure differs from that under inert conditions and at low temperatures, therefore in-situ studies are done during gas treatments and at elevated temperatures. ${ }^{23}$ Consequently, the anharmonicity of the atom vibrations should be considered.

Here, we show that in the analysis of EXAFS data of supported Pt catalysts, asymmetry of the PDF should be taken into account, especially at elevated temperatures. Our approach was to include the third and fourth cumulant as parameters in the fit. Simulations reveal errors in the fit parameters when omitting these cumulants. EXAFS spectra of supported platinum catalysts were collected up to $700 \mathrm{~K}$ in vacuum and in hydrogen atmospheres, to study the changes in the Pt clusters under catalytically relevant conditions. Analysis of these spectra leads to guidelines for the analysis of in-situ EXAFS data of supported metal catalysts. 


\section{Experimental section}

\subsection{Theoretical spectra}

Theoretical EXAFS functions were calculated with $N=6.8, R=2.73 \AA, \Delta \sigma^{2}=0.003 \AA^{2}$, and $\Delta E_{0}=2 \mathrm{eV}$. The experimentally determined phase shift, $S_{0}{ }^{2}$, and backscattering amplitude of a Pt foil were used. Either $C_{3}$ was varied between $-1 \times 10^{-3}$ and $1 \times 10^{-3} \AA^{3}$ or $C_{4}$ was varied between $-1 \times 10^{-4}$ and $1 \times 10^{-4} \AA^{4}$. These parameters are typical for small Pt clusters. The functions were calculated in the multiple shell analysis routine of the XDAP software package, ${ }^{3}$ by fixing the values of all fit parameters. The functions were analyzed without including the higher-order cumulants.

Table 1 Catalysts used in this study

\begin{tabular}{|c|c|c|c|c|c|c|}
\hline Catalyst name & $\mathrm{wt} \% \mathrm{Pt}$ & calcination $\mathrm{T}$ & reduction $\mathrm{T}$ & $\mathrm{H} / \mathrm{Pt}^{a}$ & evacuation $\mathrm{T}$ & used in XAS experiment \\
\hline $\mathrm{Pt} / \mathrm{Al}_{2} \mathrm{O}_{3}-79 \mathrm{a}$ & 2 & $673 \mathrm{~K}$ & $823 \mathrm{~K}$ & 0.79 & $573 \mathrm{~K}$ & vacuum at $77,298,473 \mathrm{~K}$, hydrogen at $298 \mathrm{~K}$ \\
\hline $\mathrm{Pt} / \mathrm{Al}_{2} \mathrm{O}_{3}-79 \mathrm{~b}$ & 2 & $673 \mathrm{~K}$ & $823 \mathrm{~K}$ & 0.79 & $673 \mathrm{~K}$ & vacuum at $263,313,373,473,573,673 \mathrm{~K}$, hydrogen at $298 \mathrm{~K}$ \\
\hline $\mathrm{Pt} / \mathrm{SiO}_{2}-57$ & 1 & $373 \mathrm{~K}$ & $473 \mathrm{~K}$ & 0.57 & $573 \mathrm{~K}$ & vacuum at $298,473 \mathrm{~K}$ \\
\hline $\mathrm{Pt} / \mathrm{K} / \mathrm{Al}_{2} \mathrm{O}_{3}-81$ & 1.5 & $523 \mathrm{~K}$ & $523 \mathrm{~K}$ & 0.81 & - & hydrogen at $283,400,530,670 \mathrm{~K}$ \\
\hline $\mathrm{Pt} / \mathrm{Al}_{2} \mathrm{O}_{3}-70$ & 1.5 & $823 \mathrm{~K}$ & $523 \mathrm{~K}$ & 0.70 & - & hydrogen at $283,400,530,670 \mathrm{~K}$ \\
\hline $\mathrm{Pt} / \mathrm{Al}_{2} \mathrm{O}_{3}-57$ & 1.5 & $523 \mathrm{~K}$ & $523 \mathrm{~K}$ & 0.57 & - & hydrogen at $283,400,530,670 \mathrm{~K}$ \\
\hline $\mathrm{Pt} / \mathrm{Al}_{2} \mathrm{O}_{3}-18$ & 1.5 & $898 \mathrm{~K}$ & $523 \mathrm{~K}$ & 0.18 & - & hydrogen at $283,400,530,670 \mathrm{~K}$ \\
\hline
\end{tabular}

\subsection{Catalyst preparation}

$\mathrm{Pt} / \mathrm{Al}_{2} \mathrm{O}_{3}$ was prepared by incipient wetness impregnation of $\gamma-\mathrm{Al}_{2} \mathrm{O}_{3}$ (Condea or Catapal) with an aqueous solution of tetra ammine platinum nitrate (PTA). After impregnation, the powders were dried and calcined at the temperatures given in Table $1 . \mathrm{Pt} / \mathrm{K} / \mathrm{Al}_{2} \mathrm{O}_{3}$ was prepared by impregnating the $\mathrm{Al}_{2} \mathrm{O}_{3}$ with an aqueous solution of $\mathrm{KNO}_{3}$. After calcination at $773 \mathrm{~K}$, the $1.5 \mathrm{wt} \% \mathrm{~K} / \mathrm{Al}_{2} \mathrm{O}_{3}$ was impregnated with an aqueous solution of PTA and calcined again. $\mathrm{Pt} / \mathrm{SiO}_{2}$ was prepared by adding an aqueous solution of PTA to a slurry of $\mathrm{SiO}_{2}$ (Davison 644) in an $\mathrm{NH}_{4} \mathrm{OH}$ solution with a $\mathrm{pH}$ of 10 . After adsorption of the PTA, the powder was filtered, washed, and dried at $373 \mathrm{~K}$. Table 1 lists all catalysts, with the 
$\mathrm{Pt}$ loading, calcination, reduction, and evacuation temperatures, $\mathrm{H} / \mathrm{Pt}$, and the experiments in which they were used.

\subsection{XAS experiments}

All the spectra were recorded in transmission mode with ion chambers for detection. A platinum foil spectrum was acquired simultaneously with each measurement for energy calibration. The spectra of $\mathrm{Pt} / \mathrm{Al}_{2} \mathrm{O}_{3}-79$ and $\mathrm{Pt} / \mathrm{SiO}_{2}-57$ were collected at beamline $\mathrm{X} 1$ of HASYLAB (Hamburg, Germany) and the DUBBLE station (BM26A) at the ESRF (Grenoble, France). At beamline X1 the double-crystal monochromator was equipped with $\operatorname{Si}(111)$ crystals that were detuned to $70 \%$ of the intensity to remove higher harmonics. At the DUBBLE station, a double-crystal monochromator was used, followed by two vertically focusing $\mathrm{Pt}$ - and Si-coated mirrors to reject the harmonics. The supported Pt catalyst was pressed into a self-supporting wafer and placed in a stainlesssteel in-situ cell. ${ }^{24}$ The catalysts were reduced in pure hydrogen at the temperature specified in Table 1 and cooled down in the hydrogen flow. The $\mathrm{L}_{3}$ XAS spectrum of Pt with chemisorbed hydrogen was collected in $200 \mathrm{kPa}$ pure hydrogen at $298 \mathrm{~K}$. Subsequently, the adsorbed hydrogen was removed by evacuation $\left(<10^{-2} \mathrm{~Pa}\right)$ at 573 or $673 \mathrm{~K}$. The $\mathrm{L}_{3}$ XAS spectra were collected at several temperatures, starting at the highest temperature. During a series of measurements, the catalyst always remained in dynamic vacuum $\left(<10^{-2} \mathrm{~Pa}\right)$. Two series were measured of $\mathrm{Pt} / \mathrm{Al}_{2} \mathrm{O}_{3}-79$, each with a fresh sample.

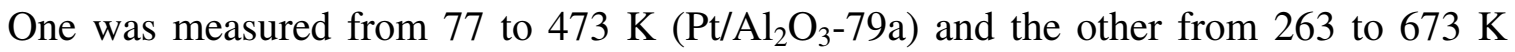
(Pt/Al $\left.{ }_{2} \mathrm{O}_{3}-79 b\right)$. Spectra of $\mathrm{Pt} / \mathrm{SiO}_{2}-57$ were collected at 298 and $473 \mathrm{~K}$.

The spectra in hydrogen of $\mathrm{Pt} / \mathrm{Al}_{2} \mathrm{O}_{3}-81,-70,-57$, and -18 were collected at the beamline of the Materials Research Collaborative Access Team (MRCAT) at the APS 
(Argonne National Laboratory, US). A double-crystal Si(111) monochromator was used in conjunction with an uncoated glass mirror to minimize the presence of harmonics. The samples were pressed into a cylindrical holder with six sample positions, and data were taken for each sample under the same conditions. The pre-reduced catalysts were rereduced at $523 \mathrm{~K}$ for $1 \mathrm{~h}$ in a $4 \% \mathrm{H}_{2} / \mathrm{He}$ flow (100 ml/min). XAS spectra were obtained in $4 \% \mathrm{H}_{2} / \mathrm{He}$ flow from 283 to $670 \mathrm{~K}$.

\subsection{Data analysis}

XAS data analysis was carried out with the commercially available XDAP software package. ${ }^{25}$ The absorption data were pre-edge and background-subtracted by means of standard procedures. ${ }^{3}$ The spectra were normalized on the height of the edge-step at 50 eV over the edge. Multiple shell fitting was performed in R-space $\left(3.2<k<13 \AA^{-1}, 1.6<\right.$ $R<3.2 \AA$ ) using $k$ weightings of 1 and 3 . Multiple scattering paths were not included. Experimentally calibrated theoretical references obtained with the FEFF8 $\operatorname{code}^{26}$ were used to obtain $S_{0}{ }^{2}, F$, and $\delta$. A platinum foil was used for the Pt-Pt reference, and $\mathrm{PtO}_{2}$ for the Pt-O reference, both measured at $298 \mathrm{~K}$.

\section{Results}

\subsection{Theoretical spectra}

Calculated EXAFS functions of small Pt clusters with asymmetric or broadened pair distributions were fitted without including the higher-order cumulants. The obtained structural parameters and the fit quality are shown in Figure 1 as a function of the input value of $C_{3}$ or $C_{4}$. The coordination number (Fig. 1a) is strongly influenced by $C_{4}$. When excluding a fourth cumulant of $5 \times 10^{-5} \AA^{4}$ an $N$ of 5.5 is determined instead of 6.8 . 
Excluding a positive $C_{4}$, thus ignoring a broadened PDF, leads to an underestimation of the coordination number. If $C_{4}$ is between $-1 \times 10^{-4}$ and $1 \times 10^{-4} \AA^{4}$ the error in $N$ is up to 40 $\%$. The Debye-Waller factor (Fig. 1b) is also strongly influenced by $C_{4}$; omitting a $C_{4}$ of $1 \times 10^{-4} \AA^{4}$ shifts $\Delta \sigma^{2}$ by $0.006 \AA^{2}$. The third cumulant hardly affects $N$ and $\Delta \sigma^{2}$.

The third cumulant has a strong effect on the distance (Fig. 1c). If a $C_{3}$ of $5 \times 10^{-4}$ $\AA^{3}$, which is reasonable at high temperatures, is omitted, a distance of $2.68 \AA$ is determined instead of the actual $2.73 \AA$. If $C_{3}$ is negative, the distance is overestimated. If $C_{3}$ is between $-1 \times 10^{-3}$ and $1 \times 10^{-3} \AA^{3}$, the error in the distance is $+/-0.1 \AA$ or $4 \%$. The inner potential correction (Fig. 1d) strongly deviates from the actual value when $C_{3}$ is ignored. The deviation is 5 to $15 \mathrm{eV}$ when a third cumulant of $+/-1 \times 10^{-3} \AA^{3}$ is neglected. The fourth cumulant does not influence the determination of $R$ and $\Delta E_{0}$. The errors are considerably higher than the accuracy that can be achieved in EXAFS analysis.

The fit quality (Fig. 1e), expressed as the variance of the $k^{3}$-weighted fit in $R$ space, ${ }^{3}$ deteriorates with increasing $C_{3}$ and $C_{4}$, thus with enhanced thermal and static disorder. The variance is hardly influenced by $C_{4}$, whereas when ignoring $C_{3}$ the fit quality is very poor. So errors in $N$ and $\Delta \sigma^{2}$ go unnoticed, whereas errors in $R$ and $\Delta E_{0}$ are directly observed from a poor fit quality.

\subsection{Influence of temperature in vacuum}

EXAFS spectra of $\mathrm{Pt} / \mathrm{Al}_{2} \mathrm{O}_{3}$ and $\mathrm{Pt} / \mathrm{SiO}_{2}$ were collected at several temperatures in vacuum (Table 1). The supported Pt clusters were metallic and no hydrogen was chemisorbed. In these series of measurements, the Pt-Pt coordination number is constant so that the temperature effect on the other structural parameters can be studied. Also, $\Delta E_{0}$ should be about the same for each spectrum, because $E_{0}$ was always chosen in the same way and no 
Table $2 \mathrm{Pt}-\mathrm{Pt}$ and Pt-O coordination number of $\mathrm{Pt}_{/} \mathrm{Al}_{2} \mathrm{O}_{3}-79 \mathrm{a}, \mathrm{Pt} / \mathrm{Al}_{2} \mathrm{O}_{3}-79 \mathrm{~b}$, and $\mathrm{Pt} / \mathrm{SiO}_{2}-57$. EXAFS analysis of $\mathrm{Pt} \mathrm{L}_{3}$ edge $\left(k^{3}\right.$ weighting, $3<k<13 \AA^{-1}$, $1.6<R<3.2 \AA$ ). The error in $N$ is $20 \%$.

\begin{tabular}{llll} 
Catalyst & fit procedure & $N_{\mathrm{Pt}-\mathrm{Pt}}$ & $N_{\mathrm{Pt}-\mathrm{O}}$ \\
\hline $\mathrm{Pt} / \mathrm{Al}_{2} \mathrm{O}_{3}-79 \mathrm{a}$ & $C_{3}=C_{4}=0$ & 5.5 & 0.3 \\
& with $C_{3}, C_{4}$ & 5.8 & 0.5 \\
$\mathrm{Pt} / \mathrm{Al}_{2} \mathrm{O}_{3}-79 \mathrm{~b}$ & $C_{3}=C_{4}=0$ & 6.0 & 0.2 \\
& with $C_{3}, C_{4}$ & 5.0 & 0.5 \\
$\mathrm{Pt} / \mathrm{SiO}_{2}-57$ & $C_{3}=C_{4}=0$ & 8.9 & 0 \\
& with $C_{3}, C_{4}$ & 6.9 & 0.2
\end{tabular}

${ }^{a}$ Assuming a Gaussian pair distribution. ${ }^{b}$ Allowing for anharmonicity and high static disorder.

significant edge shifts were observed. The Fourier-transforms (FT) of the Pt $\mathrm{L}_{3}$ EXAFS of $\mathrm{Pt} / \mathrm{Al}_{2} \mathrm{O}_{3}-79$ at six temperatures are shown in Figure 2. The FT's were phase-corrected with a Pt-Pt reference, so that the maximum should be at the correct coordination distance. The intensity of the FT decreases with increasing temperature, because the EXAFS function is dampened by the enhanced thermal disorder. Furthermore, the peak maximum shifts to lower distance with increasing temperature implying that there is a contraction of the Pt-Pt distance.

3.2.1. Coordination numbers in vacuum. $N_{\mathrm{Pt}-\mathrm{Pt}}$ did not change significantly and there was no apparent increase or decrease as function of temperature, therefore in the EXAFS analysis it was fixed at the average found value (Table 2). For $\mathrm{Pt} / \mathrm{Al}_{2} \mathrm{O}_{3}$ the coordination number was 5 to 6 . This corresponds to a cluster size of $1 \mathrm{~nm}^{27}$ and thus a dispersion of $0.86 .^{28,29}$ The measured $\mathrm{H} / \mathrm{Pt}$ of 0.79 is slightly lower than the dispersion deduced from the EXAFS fit, because H/Pt also depends on the support. The measured $\mathrm{H} / \mathrm{Pt}$ for $\mathrm{Pt} / \mathrm{SiO}_{2}$ was 0.57 , which corresponds to a cluster size of $2 \mathrm{~nm}$ and an $N$ of 9 . This is the fit result when excluding the higher-order cumulants, but $N$ is lower when the cumulants are included. The trend is correct: for $\mathrm{Pt} / \mathrm{Al}_{2} \mathrm{O}_{3} \mathrm{H} / \mathrm{Pt}$ is higher and $N_{\mathrm{Pt}-\mathrm{Pt}}$ is lower compared to $\mathrm{Pt} / \mathrm{SiO}_{2}$. Thus, the $\mathrm{Pt}$ coordination numbers are realistic. A support oxygen contribution with a coordination number of 0.2 to 0.5 was included (Table 2). These $N_{\mathrm{Pt}-\mathrm{O}}$ values are reasonable for supported metal clusters of 1 to $2 \mathrm{~nm}$ in size. Using 
the coordination numbers in Table 2 resulted in stable fits, although these values are not accurate.

We tried to fit the data as well without fixing any parameters and choosing the parameters such that the results were the same with $k^{1}$ and $k^{3}$ weighting. This was done by plotting $\Delta \sigma^{2}$ versus $N$ for both weightings and choosing the $N$ at which the two lines intersect. The same was done for $C_{3}$ versus $R$. This did not lead to stable fits for all spectra and we consider it better to keep $N$ constant with temperature. Nevertheless, checking if the fit results were similar with $k^{1}$ and $k^{3}$ weighting was done to ensure the reliability.

3.2.2. Spectra in vacuum: fits without higher-order cumulants. When fitting the spectra without higher-order cumulants the Debye-Waller factor of the oxygen shell

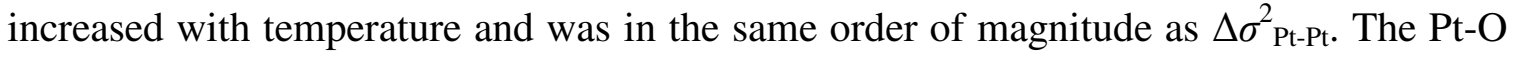
distance was 2.1 $\AA$. The fit results for the first $\mathrm{Pt}$ shell of $\mathrm{Pt} / \mathrm{Al}_{2} \mathrm{O}_{3}-79$ and $\mathrm{Pt} / \mathrm{SiO}_{2}-57$ are shown in Figure 3; those without cumulants are the open symbols. The shift in DebyeWaller factor with respect to the Pt foil value $\left(\Delta \sigma^{2}\right)$ (Fig. 3a) increases linearly with temperature due to an increase in thermal disorder. The inner potential correction (Fig. 3b) for $\mathrm{Pt} / \mathrm{Al}_{2} \mathrm{O}_{3}$ increases from 4 to $10 \mathrm{eV}$ over a temperature rise of $400 \mathrm{~K}$. For $\mathrm{Pt} / \mathrm{SiO}_{2}$ the deviation of $\Delta E_{0}$ from the expected values is less obvious.

An average Pt-Pt interatomic distance of $2.66 \AA$ was obtained for $\mathrm{Pt} / \mathrm{Al}_{2} \mathrm{O}_{3}$ at low temperature (open symbols in Fig. 3c). It decreases to $2.63 \AA$ at $673 \mathrm{~K}$. Also for $\mathrm{Pt} / \mathrm{SiO}_{2}$ the distance decreases with increasing temperature. This apparent bond contraction cannot be physically explained. Furthermore, the bulk Pt-Pt distance is $2.78 \AA$. It is lower for small clusters, due to the higher electron density between the atoms because of 
dehybridization of the spd metal orbitals. ${ }^{30}$ For an $N$ of 6 , instead of 12 in the bulk, an interatomic distance of $96 \%$ of the bulk value is reasonable. ${ }^{31}$ For platinum this would be $2.67 \AA$, thus the fitting without higher-order cumulants underestimates $R_{\mathrm{Pt}-\mathrm{Pt}}$. The distance in $\mathrm{Pt} / \mathrm{Al}_{2} \mathrm{O}_{3}-79 \mathrm{a}$ is shorter than in $\mathrm{Pt} / \mathrm{Al}_{2} \mathrm{O}_{3}-79 \mathrm{~b}$. Also, $\Delta E_{0}$ is higher and increases stronger with temperature in the first series. This stronger deviation from the expected values might be explained by the lower data quality of the spectra in the first series.

3.2.3. Spectra in vacuum: fits including higher-order cumulants. Broadening or asymmetry of the PDF was taken into account by including the higher-order cumulants. When fitting two shells the number of refined parameters has to be limited so that it does not exceed the number of free parameters, which is ten (Nyquist theorem). Not including the oxygen shell leads to an underestimation of $R_{\mathrm{Pt}-\mathrm{Pt}}$ of up to $0.05 \AA$. However, the exact values of the parameters of the oxygen shell hardly influence that of platinum, because the amplitude of the oxygen contribution is less than $10 \%$ of that of Pt. $\Delta E_{0}$ of the oxygen shell was kept equal to zero so that $R_{\mathrm{Pt}-\mathrm{O}}$ was constant at $1.94 \AA$. $C_{4}$ of the oxygen shell was kept equal to that of the Pt shell so that $\Delta \sigma^{2}$ increased with temperature. When varying $C_{4}$ of oxygen, the $\Delta \sigma^{2}$ became very large, and no stable fits were obtained. With these restrictions stable fits were obtained with physically meaningful results that were practically the same with $k^{1}$ and $k^{3}$ weighting.

The Pt-Pt Debye-Waller factors are different compared to the fits without higherorder cumulants, but the trends are similar (Fig. 3a). $\Delta \sigma_{\mathrm{Pt}}^{2}$ of $\mathrm{Pt} / \mathrm{SiO}_{2}$ is lower than for $\mathrm{Pt} / \mathrm{Al}_{2} \mathrm{O}_{3}$, because the Pt clusters in $\mathrm{Pt} / \mathrm{SiO}_{2}$ are bigger. $\Delta E_{0, \mathrm{Pt}}$ for all spectra is similar and close to $0 \mathrm{eV}$ (Fig. 3b). $R_{\mathrm{Pt}-\mathrm{Pt}}$ in $\mathrm{Pt} / \mathrm{Al}_{2} \mathrm{O}_{3}$ is $2.68 \AA$ (filled symbols in Fig. $3 \mathrm{c}$ ). It is the 
same for both catalysts and constant with temperature, in contrast to fitting without cumulants. In $\mathrm{Pt} / \mathrm{SiO}_{2}$ the distance is $2.73 \AA$ at both temperatures. These are realistic values for Pt clusters of 1 to $2 \mathrm{~nm}$ in size. A bond lengthening due to thermal expansion was not observed. The Pt-Pt distance and $\Delta E_{0}$ are clearly wrong when not including the higher-order cumulants.

The third cumulant (Fig. 3d) is in the order of $10^{-4} \AA^{3}$ and increases linearly with temperature. The slope of $C_{3}$ versus temperature is the same for all three catalysts. The fourth cumulant is in the order of $+/-10^{-5} \AA^{4}$. There is no trend in the fourth cumulant versus temperature and $C_{4}$ is an order of magnitude smaller than $C_{3}$. In literature, for $\mathrm{CuBr}$ and for $\beta$-AgI third and fourth cumulants were determined that are in the same order of magnitude and increase with temperature, thus our values seem sensible. ${ }^{8,12}$

Table 3 Fit quality of the $k^{3}$-weighted EXAFS fits of the supported Pt catalysts in vacuum, without and with higher-order cumulants. $\left(3.2<k<13 \AA^{-1}, 1.6\right.$ $<\mathrm{R}<3.1 \AA$ ).

\begin{tabular}{|c|c|c|c|}
\hline \multirow[b]{2}{*}{ catalyst } & \multirow[b]{2}{*}{$\mathrm{T}(\mathrm{K})$} & \multicolumn{2}{|c|}{ variance absolute FT (\%) } \\
\hline & & $C_{3}=C_{4}=0$ & with $C_{3}, C_{4}$ \\
\hline \multirow[t]{3}{*}{$\mathrm{Pt} / \mathrm{Al}_{2} \mathrm{O}_{3}-79 \mathrm{a}$} & 77 & 0.14 & 0.007 \\
\hline & 298 & 0.27 & 0.003 \\
\hline & 473 & 0.12 & 0.01 \\
\hline \multirow[t]{6}{*}{$\mathrm{Pt} / \mathrm{Al}_{2} \mathrm{O}_{3}-79 \mathrm{a}$} & 263 & 0.16 & 0.02 \\
\hline & 313 & 0.16 & 0.01 \\
\hline & 373 & 0.14 & 0.01 \\
\hline & 473 & 0.28 & 0.04 \\
\hline & 573 & 0.24 & 0.04 \\
\hline & 673 & 0.67 & 0.05 \\
\hline \multirow[t]{2}{*}{$\mathrm{Pt} / \mathrm{SiO}_{2}-57$} & 298 & 0.06 & 0.003 \\
\hline & 473 & 0.09 & 0.005 \\
\hline
\end{tabular}

\subsubsection{Fit quality. Figure 4 shows the $\mathrm{FT}$ of $\mathrm{Pt} / \mathrm{Al}_{2} \mathrm{O}_{3}-79$ at $673 \mathrm{~K}$ and the best fits} with and without higher-order cumulants. The fit and the experimental data are clearly in much better agreement when $C_{3}$ and $C_{4}$ are included. Table 3 lists the variances in the absolute part of the spectrum; the variances in the real part were of the same order of magnitude. The fit quality deteriorates with increasing temperature without the higher- 
order cumulants. For all fits the variances are lower and hardly depend on temperature when including the higher-order cumulants.

3.2.5. Chemisorption of hydrogen. Prior to collecting the above described spectra in vacuum spectra of $\mathrm{Pt} / \mathrm{Al}_{2} \mathrm{O}_{3}-79$ in hydrogen at $298 \mathrm{~K}$ were taken. The adsorption of molecules on supported metal clusters can affect cluster morphology, interatomic distances, and electronic state of the metal,24,32,33 which is relevant for the catalytic properties. Hydrogen is a primary reactant in many catalytic reactions over supported Pt. When fitting the EXAFS spectra obtained in hydrogen, $N$ cannot be fixed; therefore, other parameters were fixed. $C_{4, \mathrm{O}}$ was again held the same as $C_{4, \mathrm{Pt}}$ and $\Delta E_{0, \mathrm{O}}=$ $0 \mathrm{eV} . C_{3}$, Pt-Pt was chosen the same as that of the same catalyst in vacuum at $298 \mathrm{~K}$, since $C_{3}$ depends on temperature. Changing $C_{3}$ slightly $\left(+/-0.5 \times 10^{-4} \AA^{3}\right)$ caused a change of only about $0.1 \%$ in $R_{\mathrm{Pt}-\mathrm{Pt}}$ and of 0.3 in $N_{\mathrm{Pt}-\mathrm{Pt}}$, thus $C_{3}$ can be fixed. Stable fits were obtained. Upon hydrogen chemisorption, the contracted Pt-Pt bond expands by $0.05 \AA$ to $2.73 \AA$. The other structural parameters did not differ significantly from those in vacuum. If $C_{3}$ is not included, $R_{\mathrm{Pt}-\mathrm{Pt}}$ is underestimated by $0.03 \AA$ and $\Delta E_{0}$ is $4 \mathrm{eV}$ instead of around $1 \mathrm{eV}$.

\subsection{Influence of temperature in hydrogen atmosphere}

XAS spectra of $\mathrm{Pt} / \mathrm{Al}_{2} \mathrm{O}_{3}$ catalysts with various cluster sizes were collected in flowing hydrogen at increasing temperatures. One of the catalysts contains $\mathrm{K}$ on the $\mathrm{Al}_{2} \mathrm{O}_{3^{-}}$ support; however, it does fit in the series of supported Pt clusters. The coordination number and distance are expected to vary with temperature, because of the chemisorption of hydrogen at low temperature and desorption at high temperature. The XANES at 283, 400,530 , and $670 \mathrm{~K}$ of the four $\mathrm{Pt} / \mathrm{Al}_{2} \mathrm{O}_{3}$ catalysts in $4 \% \mathrm{H} / 2 / \mathrm{He}$ are shown in Figure 5. 
Hydrogen chemisorption induces a change in the XANES. 33,34 The intensity of this change decreases with decreasing dispersion and thus increasing cluster size. Hydrogen desorption occurs between 530 and $670 \mathrm{~K}$, which is consistent with literature results. ${ }^{35}$ The measurements were done in $4 \% \mathrm{H}_{2} / \mathrm{He}$, so there might still be hydrogen chemisorbed at $670 \mathrm{~K}$. Sintering did not occur, as was checked with hydrogen chemisorption experiments.

Table 4 Debye-Waller factor of the Pt coordination shell as function of temperature for $\mathrm{Pt} / \mathrm{Al}_{2} \mathrm{O}_{3}$ as used in the EXAFS analysis

$$
C_{3}=C_{4}=0 \quad \text { with } C_{3}, C_{4}
$$

$\mathrm{T}(\mathrm{K}) \quad$ small clusters ${ }^{a}$ large clusters ${ }^{b}$ small clusters large clusters $\begin{array}{llll}\left(10^{-3} \AA^{2}\right) & \left(10^{-3} \AA^{2}\right) & \left(10^{-3} \AA^{2}\right) & \left(10^{-3} \AA^{2}\right)\end{array}$

\begin{tabular}{lllll}
\hline 283 & 2.9 & 0.21 & 3.5 & -1.4 \\
400 & 4.7 & 2.0 & 5.5 & 0.9 \\
530 & 6.6 & 4.1 & 7.7 & 3.6 \\
670 & 8.8 & 6.4 & 10 & 6.4
\end{tabular}

${ }^{a} \mathrm{Pt} / \mathrm{Al}_{2} \mathrm{O}_{3}-81,-70,-57 .{ }^{b} \mathrm{Pt} / \mathrm{Al}_{2} \mathrm{O}_{3}-18$.

3.3.1. Spectra in hydrogen: data analysis. To restrict the number of fit parameters, some parameters had to be fixed. The Debye-Waller factor depends linearly on temperature and two groups of catalysts were discerned. The three catalysts with the smallest Pt clusters $\left(\mathrm{Pt} / \mathrm{Al}_{2} \mathrm{O}_{3}-81,-70,-57\right)$ had about the same Debye-Waller factors, which were higher than those of the larger clusters $\left(\mathrm{Pt} / \mathrm{Al}_{2} \mathrm{O}_{3}-18\right)$. The slope of $\Delta \sigma^{2}$ versus temperature was the same in both groups. The Debye-Waller factor at each temperature was fixed and held the same within one group of catalysts (Table 4). This does not affect the trend in $N$. Approximately the same Pt coordination numbers were obtained with $k^{1}$ and $k^{3}$ weighting. For the smallest Pt clusters, a support oxygen contribution with a fixed value had to be included (Table 5). When including the higher-order cumulants in the fit, $E_{0, \text { oxygen }}$ was constrained to zero and $C_{4}$ was kept the same for both shells. With these constraints, good, stable fits with physically meaningful results were generally obtained. For $\mathrm{Pt} / \mathrm{Al}_{2} \mathrm{O}_{3}-57$ at $670 \mathrm{~K}$ this procedure still gave results that were not in line with those 
at the other three temperatures and the fit was unstable. Overall, the third cumulant increases linearly with temperature, which was also the case for this catalyst if the spectrum at $670 \mathrm{~K}$ was left out. Thus, $C_{3}$ for this spectrum was chosen to be on the straight line through the other values of $C_{3}$ versus temperature (Fig. 7c). In this way, $\Delta E_{0}$, Pt was always close to zero, and $R_{\mathrm{Pt}-\mathrm{Pt}}$ was physically meaningful.

3.3.2. Coordination numbers in hydrogen. Table 5 lists the coordination numbers. The expected $N_{\mathrm{Pt}-\mathrm{Pt}}$ is deduced from the $\mathrm{H} / \mathrm{Pt}$ values as given in Table 1 , assuming spherical clusters. ${ }^{27-29} \mathrm{~N}$ is about the same with and without cumulant (in this section the $N_{\mathrm{Pt}-\mathrm{Pt}}$ determined with cumulants is referred to). The coordination number of the catalysts with chemisorbed hydrogen is about the same as the expected $N$, except for $\mathrm{Pt} / \mathrm{Al}_{2} \mathrm{O}_{3}-18$. As discussed before, the measured $\mathrm{H} / \mathrm{Pt}$ might be lower than the real dispersion. Also, in sample $\mathrm{Pt} / \mathrm{K} / \mathrm{Al}_{2} \mathrm{O}_{3}-81$ potassium is present on the support, which enhances the ratio of strong over total $\mathrm{H} / \mathrm{Pt}, 36$ thus $\mathrm{H} / \mathrm{Pt}$ of this sample is actually lower than 0.81. Considering this, the trend is right: $N$ increases with decreasing $\mathrm{H} / \mathrm{Pt}$. The $\mathrm{Pt}-\mathrm{Pt}$ coordination number decreases upon hydrogen desorption, especially for $\mathrm{Pt} / \mathrm{Al}_{2} \mathrm{O}_{3}-57$ with intermediate cluster size. $N$ of the largest clusters $\left(\mathrm{Pt} / \mathrm{Al}_{2} \mathrm{O}_{3}-18\right)$ does not change with hydrogen coverage.

Table 5 Coordination numbers of $\mathrm{Pt} / \mathrm{Al}_{2} \mathrm{O}_{3}$ measured in hydrogen atmosphere at temperatures from 283 to $670 \mathrm{~K}$. See text for details $\left(3<k<12.5 \AA^{-1}, 1.7\right.$ $<R<3.2 \AA$ ). Error in $N$ is $15 \%$.

\begin{tabular}{|c|c|c|c|c|c|c|}
\hline & & & $N_{\text {Pt-Pt }}$ with & hydrogen & $N_{\mathrm{Pt}-\mathrm{Pt}}$ without hydrogen ${ }^{b}$ & \\
\hline catalyst & $N_{\mathrm{Pt}-\mathrm{O}}$ & expected $N_{\mathrm{Pt}-\mathrm{Pt}}^{a}$ & $C_{3}=C_{4}=0$ & with $C_{3}, C_{4}$ & $C_{3}=C_{4}=0 \quad$ with $C_{3}, C_{4}$ & \\
\hline$\overline{\mathrm{Pt} / \mathrm{K} / \mathrm{Al}_{2} \mathrm{O}_{3}-81}$ & 0.2 & 7 & 7.5 & 7.9 & 8.0 & \\
\hline $\mathrm{Pt} / \mathrm{Al}_{2} \mathrm{O}_{3}-70$ & 0.5 & 8.5 & 6.7 & 7.3 & 6.7 & \\
\hline $\mathrm{Pt} / \mathrm{Al}_{2} \mathrm{O}_{3}-57$ & & 9.5 & 8.4 & 8.5 & 7.2 & \\
\hline $\mathrm{Pt} / \mathrm{Al}_{2} \mathrm{O}_{3}-18$ & & 11 & 9.5 & 8.9 & 9.0 & \\
\hline
\end{tabular}


3.3.3. Spectra in hydrogen: fits without higher-order cumulants. The $\mathrm{Pt}-\mathrm{Pt}$ distance and $E_{0}$ correction obtained from fitting without higher-order cumulants are shown in Figure 6. The obtained average distance for the three $\mathrm{Pt} / \mathrm{Al}_{2} \mathrm{O}_{3}$ catalysts with the smaller clusters is about $2.73 \AA$ at $283 \mathrm{~K}$ (Fig. 6a). It decreases strongly with temperature to $2.62 \AA$ at $670 \mathrm{~K}$. This is only $94 \%$ of the bulk value, thus remarkably low. The inner potential corrections (Fig. 6b) increase with temperature, from about $1 \mathrm{eV}$ at $283 \mathrm{~K}$ to about $12 \mathrm{eV}$ at $670 \mathrm{~K}$. The increase is the strongest for the catalyst with the lowest $N$, thus the smallest Pt clusters. Hydrogen desorption shifts the edge position, but only by less than $1 \mathrm{eV}$. Thus, $E_{0}$ corrections of more than a few $\mathrm{eV}$ and a change with temperature are unlikely, proving that the asymmetry of the PDF should be taken into account. For the catalyst with larger clusters $\left(\mathrm{Pt} / \mathrm{Al}_{2} \mathrm{O}_{3}-18\right)$ the $E_{0}$ corrections are around zero and $R$ decreases slightly with temperature.

3.3.4. Spectra in hydrogen: fits including higher-order cumulants. The Pt-Pt distance when including the cumulants is constant up to $530 \mathrm{~K}$ (Fig. 7a). It is $2.75 \AA$, except for $\mathrm{Pt} / \mathrm{Al}_{2} \mathrm{O}_{3}-70$ it is $2.73 \AA$, which is the catalyst with the lowest $N$. Upon hydrogen desorption $(670 \mathrm{~K}) R_{\mathrm{Pt}-\mathrm{Pt}}$ contracts in all catalysts. Thus, whereas $R$ seems to decrease steadily with temperature when not including the cumulants, in reality the distance only contracts upon hydrogen desorption. The bond contraction is 0.02 to 0.04 $\AA$. The $E_{0}$ correction is close to $0 \mathrm{eV}$ and constant with temperature (Fig. 7b). For the catalysts with smaller Pt clusters the third cumulant is in the order of $10^{-4}$ to $10^{-3} \AA^{3}$, which is the same order as for the catalysts in vacuum (Fig. 7c). It increases linearly with temperature and the slope is roughly the same for these three catalysts. $C_{3}$ is around zero for the catalyst with the largest clusters $\left(\mathrm{Pt} / \mathrm{Al}_{2} \mathrm{O}_{3}-18\right)$. The fourth cumulant is between - 
$4 \times 10^{-5}$ and $9 \times 10^{-5} \AA^{4}$ and on the whole increases with temperature (Fig. 7d). However, $C_{4}$ of $\mathrm{Pt} / \mathrm{Al}_{2} \mathrm{O}_{3}-70$ is the highest at the lowest temperature, but fixing $C_{4}$ at a lower value lead to unstable fits. $C_{4}$ is negative for the largest Pt clusters, and generally positive for the smaller clusters.

\section{Discussion}

\subsection{Effect of anharmonicity and high disorder}

In the analysis of spectra of supported Pt catalysts measured in vacuum with the standard EXAFS equation, the average Pt-Pt distance is underestimated and seems to decrease by $0.03 \AA$ over $400 \mathrm{~K}$. A contraction of $0.12 \AA$ over $400 \mathrm{~K}$ was obtained for the spectra measured in hydrogen. This apparent bond contraction with increasing temperature has been observed before. $5,11,13,19,37,38$ Marques et al. observed a bond contraction of 0.03 $\AA$ Aver a temperature rise of $600 \mathrm{~K}$ for small Pt clusters on $\mathrm{SiO}_{2} \cdot{ }^{7}$ Their two-shell approach revealed that the discrepancy is mainly due to the enhanced thermal motion of the surface atoms. Furthermore, the $E_{0}$ correction in nearly all our spectra is more than a few $\mathrm{eV}$ and increases with temperature. The fit quality is poor, especially at high temperature. Thus asymmetry and broadening of the pair distribution function have to be allowed for. For Ir clusters on $\gamma-\mathrm{Al}_{2} \mathrm{O}_{3}$ the Gaussian PDF is valid for temperatures up to at least $573 \mathrm{~K}, 10$ whereas in our case asymmetry of the PDF is already present below room temperature. Whether or not anharmonicity of the atom vibrations plays a role, depends on the metal and the structure. ${ }^{10}$

We allowed for anharmonicity by including the third and fourth cumulant as parameters in the fit. ${ }^{4,6,8-10} C_{4}$ corrects errors in the coordination number and the Debye- 
Waller factor and $C_{3}$ corrects the distance and the inner potential correction. By comparing the structural parameters obtained when fitting with and without these cumulants, we found that the error in the Debye-Waller factor can be $+/-0.003 \AA^{2}$. The error in the coordination number is up to $20 \%$. However, a large under- or overestimation of $N$ was not observed and there was no apparent decrease or increase of $N$ with temperature. The interatomic distance can be under- or overestimated by several hundredths of Angströms, which is significant if the contraction or relaxation of metal bonds within the clusters is studied. This is especially relevant in in-situ studies of supported metal catalysts. The bond distance in the catalytic clusters changes in the presence of hydrogen, $\mathrm{CO}$, and other reactants, intermediates, and products. These morphology changes differ with temperature, making an accurate determination of the structural parameters crucial. The inner potential correction, which should be close to zero if $E_{0}$ is always chosen in the same way, can be up to $10 \mathrm{eV}$ when ignoring asymmetry. Since $\Delta E_{0}$ of the metal can also be a function of the catalytic conditions a correct determination is important. The errors in $R$ and $\Delta E_{0}$ increase with temperature, which is reflected in a linear increase of $C_{3}$ with temperature. This increase of $C_{3}$ with temperature was also found in literature. ${ }^{12}$ Thus, the PDF becomes more asymmetric with increasing temperature. The Pt-Pt interatomic distance and $\Delta E_{0}$ are more realistic when including the cumulants in the fit. In the case of Pt clusters the third cumulant is more important than the fourth cumulant, both for the fit parameters and the fit quality. In other words, asymmetry of the pair distribution function is more significant than broadening or sharpening. 
The errors are smaller for large Pt clusters in which most of the atoms are in the bulk. The pair distribution function is then more symmetric compared to a cluster with most atoms on the surface, which is reflected in a $C_{3}$ closer to zero. For the largest $\mathrm{Pt}$ clusters $C_{3}$ is negative. In a large cluster more than half of the atoms are in the bulk. These atoms in the core of the cluster have a smaller vibrational amplitude than the atoms on the surface. The distance distribution is asymmetric with the maximum shifted to lower distance compared to a Gaussian shape. When assuming that the distribution is Gaussian, the average distance is overestimated. For small clusters the shape of the distance distribution is the mirror image of that of a large cluster, thus the third cumulant, which allows for asymmetry, has the opposite sign and the distance is underestimated when assuming a symmetric distribution of distances.

\subsection{How to recognize anharmonicity}

The standard EXAFS equation is only valid in the small disorder limit, i.e. $k^{2} \sigma^{2}<<1$. When analyzing data up to $k=15 \AA^{-1}$ this means that if $\Delta \sigma^{2}>0.004 \AA^{2}$ the Debye-Waller factor does not give an accurate representation of the disorder in the pair distribution function. A large $\Delta E_{0}$, which is not due to an edge shift for the investigated sample compared to the reference material, suggests that anharmonicity has to be taken into account. Also, a short interatomic distance that cannot be physically explained is an indication. The structural parameters obtained from the EXAFS fit should be compared to the results from other techniques (chemisorption, TEM, XRD) to recognize whether or not the fit results are realistic. Moreover, the fit results obtained with different $k$ weighting should be similar. Furthermore, poor fits of good data indicate that asymmetry and broadening of the PDF may play a role. 


\subsection{Fitting EXAFS data collected at elevated temperatures}

Several ways to allow for the anharmonicity of the atom movements and high static disorder, and thus an asymmetric or broadened PDF, have been proposed. Eisenberger and Brown improved the accuracy of the distance determination by extending the expression for the phase function. ${ }^{5}$ Sandstrom et al. developed a procedure based on parallel analysis of experimental data and model spectra derived from a variable pair interaction potential. ${ }^{38}$ Clausen et al. focussed on the errors in the coordination number and thus size determination of supported $\mathrm{Cu}$ and Pt clusters. They proposed a model based on molecular dynamic simulations, which gave more reliable results than analysis with the standard EXAFS equation, and with the cumulant expansion approach. 2,39 Significant deviations that increase with temperature were found, which we did not observe. This might be because the PDF of Pt nanoclusters is more Gaussian-like compared to e.g. $\mathrm{Cu},{ }^{40}$ or because of the metal-support interaction. ${ }^{2}$ We also saw that omitting the fourth cumulant, which corrects errors in the coordination number, does not lead to poor fit quality for spectra of Pt clusters. Shido et al. did a quantitative higher shell analysis of highly dispersed $\mathrm{Ni} / \mathrm{Al}_{2} \mathrm{O}_{3}$ catalysts by constructing a sum of contributions in such a way that it fitted the experimental data. ${ }^{18}$ Although this method provides detailed information on the size and shape of metal clusters, it is too elaborate to carry out in every in-situ study. Frenkel et al. also focussed on the cluster size determination, of supported Pt nanoclusters. ${ }^{19}$

A convenient way to allow for anharmonicity is to add the third and fourth cumulants as parameters in the EXAFS fit. ${ }^{4,6,8-10}$ When including $C_{3}$ and $C_{4}$ there are more fit parameters. If more than one shell is involved the number of parameters may 
exceed the number of free parameters. Completely free fits will give inconsistent results for large series of related samples; therefore, the number of fit parameters has to be limited by fixing some parameters. The coordination number can be fixed if the cluster size and shape are known from other techniques. If $N$ is unknown or varies during the insitu experiments, the Debye-Waller factor at each temperature can be fixed. The Pt-Pt Debye-Waller factor in Pt clusters increases linearly with temperature. It has been proposed that for small supported Pt clusters the thermal factor for all samples should be similar at each temperature. ${ }^{19}$ In another study, $\Delta \sigma^{2}$ of lead increases linearly with temperature $\left(10^{-4} \AA^{2} / \mathrm{K}\right)$ up to the melting temperature. ${ }^{41}$ The Debye-Waller factor for large clusters should be chosen lower than for smaller clusters, because the structural disorder is lower. We have shown that it is important to measure series of catalysts, so that trends can be identified. Finally, the fit results with different $k$ weightings should be similar.

\subsection{Hydrogen chemisorption on supported Pt catalysts}

The fit guidelines as described above were used to determine the Pt-Pt bond length in $\mathrm{H}_{2}$ atmosphere as a function of temperature and thus $\mathrm{H}$ coverage, which is relevant to catalysis. Without chemisorbed hydrogen (at $670 \mathrm{~K}$ ), the interatomic distance in the small Pt clusters on $\mathrm{Al}_{2} \mathrm{O}_{3}$ is $2.68 \AA$. Thus the Pt-Pt bond is contracted by $0.10 \AA$ compared to bulk Pt. In the bigger clusters on either $\mathrm{Al}_{2} \mathrm{O}_{3}$ or $\mathrm{SiO}_{2}$ it is 2.72 or $2.73 \AA$. The Pt-Pt bond relaxes upon hydrogen chemisorption, because of the electron-withdrawing properties of chemisorbed $\mathrm{H}$ that leads to a reduced electron-density between the atoms. The bond lengthening is $0.04 \AA$ for small clusters with a Pt-Pt $N$ around 6. In larger Pt clusters, the lengthening is 0.02 to $0.03 \AA$. The effect is the same in $4 \% \mathrm{H}_{2}$ as in pure $\mathrm{H}_{2}$, for clusters 
of similar size. This is consistent with the surface coverage being almost the same at 0.04 and 1 bar, as known from hydrogen chemisorption isotherms. The relaxation due to $\mathrm{H}$ chemisorption has been observed before in similar experiments. 33

\section{Conclusions}

When fitting EXAFS data that are collected at elevated temperatures, as in in-situ catalysis measurements, anharmonicity of the atom vibrations may play a role. Also, the structural disorder in highly dispersed supported metal clusters is high. Not allowing for this may lead to poor fits and incorrect results. A straightforward correction method is to include the third and fourth cumulant as fit parameters. The third cumulant corrects the interatomic distance and the inner potential, while the fourth cumulant corrects the Debye-Waller factor and the coordination number. When including these higher-order cumulants, good data quality is indispensable because more parameters have to be fitted. Furthermore, one has to be careful that the number of fit parameters does not exceed the number of free parameters. We have presented guidelines for the analysis of elevated temperature EXAFS data of supported metal catalysts, in which the higher-order cumulants are included. These involve the identification of trends over series of samples or varying conditions, and the agreement of fit results with different $k$ weightings. Applying this to supported Pt catalysts revealed that the Pt-Pt bond length is different under catalytic conditions than under to inert atmosphere. 


\section{Acknowledgements}

The authors thank Hasylab (Hamburg, Germany) and the European Synchrotron

Radiation Facility (Grenoble, France) for provision of synchrotron radiation facilities, and the staff of Station X1 at Hasylab (Project number I-04-087) and the Dutch-Belgian Beamline at the ESRF (Experiment number $\mathrm{CH}$-1961) for their support. The work at Hasylab was supported by the European Community - Research Infrastructure Action under the FP6 "Structuring the European Research Area" Program, contract RII3-CT2004-506008. Use of the Advanced Photon Source was supported by the US Department of Energy, Office of Science, Office of Basic Energy Sciences, under Contract No. W31-109-ENG-38. MRCAT operations are supported by the Department of Energy and the MRCAT member institutions. The Swiss National Science Foundation funded this work.

\section{References}

1 R. Prins and D. C. Koningsberger, In X-ray Absorption: Principles, Applications, Techniques of EXAFS, SEXAFS and XANES, ed. D. C. Koningsberger and R. Prins, John Wiley \& Sons, New York, 1988, pp. 321-373.

2 B. S. Clausen and J. K. Nørskov, Top. Catal., 2000, 10, 221-230.

3 D. C. Koningsberger, B. L. Mojet, G. E. van Dorssen and D. E. Ramaker, Top. Catal., 2000, 10, 143-155.

4 E. D. Crozier, J. J. Rehr and R. Ingalls, In X-ray Absorption: Principles, Applications, Techniques of EXAFS, SEXAFS and XANES, ed. D. C. Koningsberger and R. Prins, John Wiley \& Sons, New York, 1988, pp. 373-442.

5 P. Eisenberger and G. S. Brown, Sol. Stat. Comm., 1979, 29, 481-484.

6 G. Bunker, Nucl. Instrum. Methods., 1983, 207, 437-444.

7 E. C. Marques, D. R. Sandstrom, F. W. Lytle and R. B. Greegor, J. Chem. Phys., 1982, 77, 1027-1034.

8 J. M. Tranquada and R. Ingalls, Phys. Rev. B, 1983, 28, 3520-3528.

9 E. D. Crozier, Nucl. Instrum. Methods Phys. Res. B, 1997, 133, 134-144.

10 G. E. van Dorssen and D. C. Koningsberger, Phys. Chem. Chem. Phys., 2003, 5, 35493556.

11 E. D. Crozier and A. J. Seary, Can. J. Phys., 1980, 58, 1388-1399. 
12 G. Dalba, P. Fornasini and F. Rocca, Phys. Rev. B, 1993, 47, 8502-8514.

13 R. B. Greegor and F. W. Lytle, Phys. Rev. B, 1979, 20, 4902-4907.

14 G. Dalba, P. Fornasini, R. Grisenti and J. Purans, Phys. Rev. Lett., 1999, 82, 42404243.

15 R. Ryoo, S. J. Cho, C. Pak and J. Y. Lee, Catal. Lett., 1993, 20, 107-115.

16 N. Allali, E. Prouzet, A. Michalowicz, V. Gaborit, A. Nadiri and M. Danot, Appl. Catal. A: Gen., 1997, 159, 333-354.

17 M. M. Günter, T. Ressler, R. E. Jentoft and B. Bems, J. Catal., 2001, 203, 133-149.

18 T. Shido, M. Lok and R. Prins, Topics in Catal., 1999, 8, 223-236.

19 A. I. Frenkel, C. W. Hills and R. G. Nuzzo, J. Phys. Chem. B, 2001, 105, 1268912703.

20 C. Lamberti, G. Turnes Palomino, S. Bordiga, A. Zecchina, G. Spanò and C. Otero Areán, Catal. Lett., 1999, 63, 213-216.

21 G. Berlier, G. Spoto, P. Fisicaro, S. Bordiga, A. Zecchina, E. Giamello and C.

Lamberti, Microchem. J., 2002, 71, 101-116.

22 S. Diaz-Moreno, D. C. Koningsberger and A. Munoz-Páez, Nucl. Instrum. Methods Phys. Res. B, 1997, 133, 134-144.

23 J. A. van Bokhoven, T. Ressler, F. M. F. de Groot and G. Knopp-Gericke, In In-situ spectroscopy of catalysts, ed. B. M. Weckhuysen, American Scientific Publishers, Stevenson Range, California, 2004, pp. 123-144.

24 M. Vaarkamp, B. L. Mojet, M. J. Kappers, J. T. Miller and D. C. Koningsberger, J. Phys. Chem., 1995, 99, 16067-16075.

25 M. Vaarkamp, J. C. Linders and D. C. Koningsberger, Phys. B, 1995, 208\&209, 159160.

26 S. I. Zabinsky, J. J. Rehr, A. Ankudinov, R. C. Albers and M. J. Eller, Phys. Rev. B, 1995, 52, 2995-3009.

27 J. de Graaf, A. J. van Dillen, K. P. de Jong and D. C. Koningsberger, J. Catal., 2001, 203, 307-321.

28 M. Primet, J. M. Basset, E. Garbowski and M. V. Mathieu, J. Am. Chem. Soc., 1975, 97, 3655-3659.

29 B. J. Kip, F. B. M. Duivenvoorden, D. C. Koningsberger and R. Prins, J. Catal., 1987, 105, 26-38.

30 B. Delley, D. E. Ellis, A. J. Freeman, E. J. Baerends and D. Post, Phys. Rev. B, 1983, 27, 2132-2144.

31 D. F. Shriver, P. W. Atkins and C. H. Langford Inorganic Chemistry, Oxford University Press, Oxford, 1994.

32 A. M. Argo, J. F. Odzak, F. S. Lai and B. C. Gates, Nature, 2002, 415, 623-626.

33 M. K. Oudenhuijzen, J. H. Bitter and D. C. Koningsberger, J. Phys. Chem. B, 2001, 105, 4616-4622.

34 A. L. Ankudinov, J. J. Rehr, J. Low and S. R. Bare, Phys. Rev. Lett., 2001, 86, $1642-$ 1645.

35 R. Giannantonio, V. Ragaini and P. Magni, J. Catal., 1994, 146, 103-115.

36 M. K. Oudenhuijzen, J. A. van Bokhoven, J. T. Miller, D. E. Ramaker and D. C.

Koningsberger, J. Am. Chem. Soc., 2005, 127, 1530-1540.

37 G. H. Via, J. H. Sinfelt and F. W. Lytle, J. Chem. Phys., 1979, 71, 690-699. 
38 D. R. Sandstrom, E. C. Marques, V. A. Biebesheimer, F. W. Lytle and R. B. Greegor, Phys. Rev. B, 1985, 32, 3541-3548.

39 B. S. Clausen, L. Gråbæk, H. Topsøe, L. B. Hansen, P. Stoltze, J. K. Nørskov and O. H. Nielsen, J. Catal., 1992, 141, 368-379.

40 B. S. Clausen, H. Topsøe, L. B. Hansen, P. Stoltze and J. K. Nørskov, Catal. Today, 1994, 21, 49-55.

41 A. E. Stern, P. Livins and Z. Zhang, Phys. Rev. B, 1991, 43, 8850-8860. 

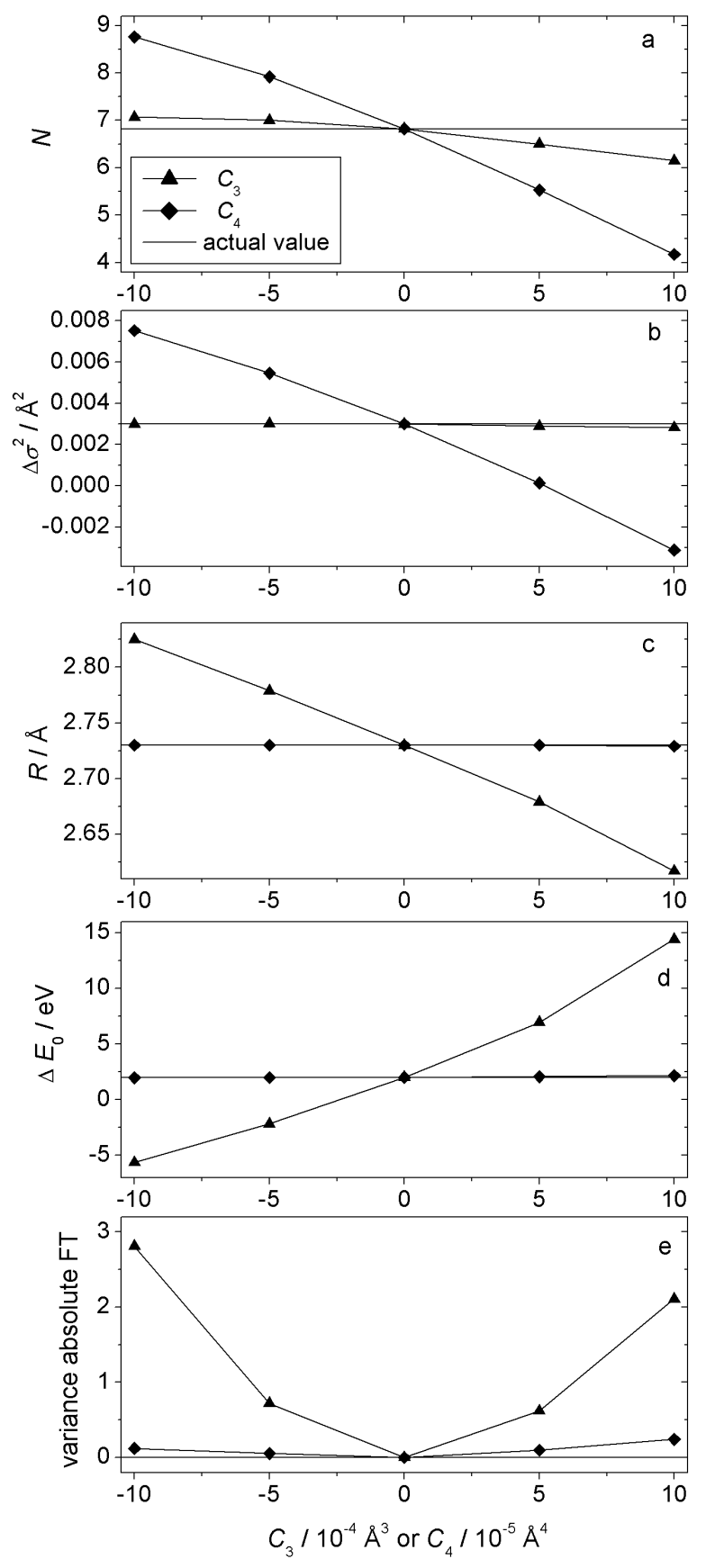

Fig. 1 Fit results when omitting cumulants of data that contain either $C_{3}(\boldsymbol{\Delta})$ or $C_{4}(\bullet)$. (a) coordination number, (b) $\Delta \sigma^{2}$, (c) interatomic distance, (d) $E_{0}$ correction, and (e) variance. The actual value of each parameter is plotted as well (horizontal line). Errors: $20 \%$ in $N, 0.003 \AA^{2}$ in $\Delta \sigma^{2}, 1 \%$ in $R, 1 \mathrm{eV}$ in $\Delta E_{0}$. 


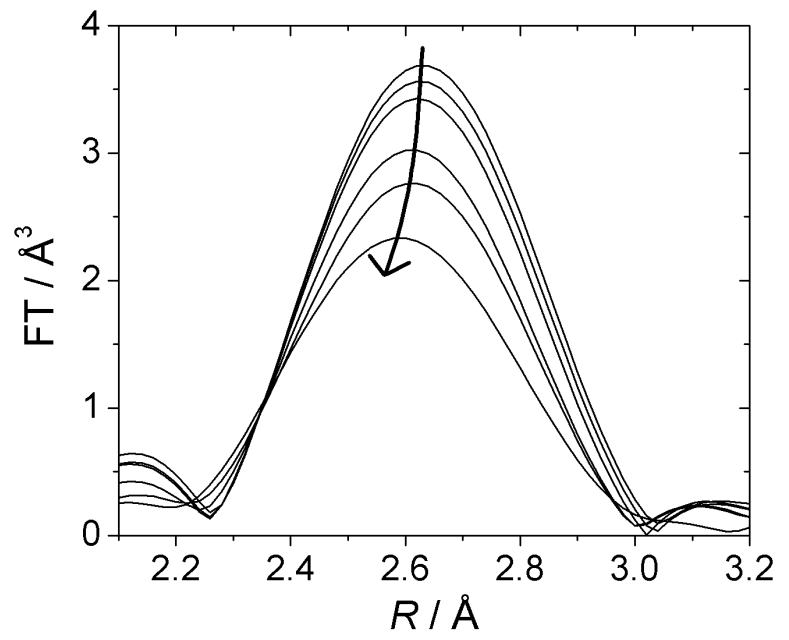

Fig. 2 Absolute magnitude of the phase-corrected Fourier-transforms of $\mathrm{Pt} / \mathrm{Al}_{2} \mathrm{O}_{3}-79$ at $263,313,373,473,573$, and $673 \mathrm{~K}$ (direction of arrow), in vacuum. $k=3.2-13 \AA^{-1} ; k^{3}$ weighting; phase correction with a Pt-Pt reference. 


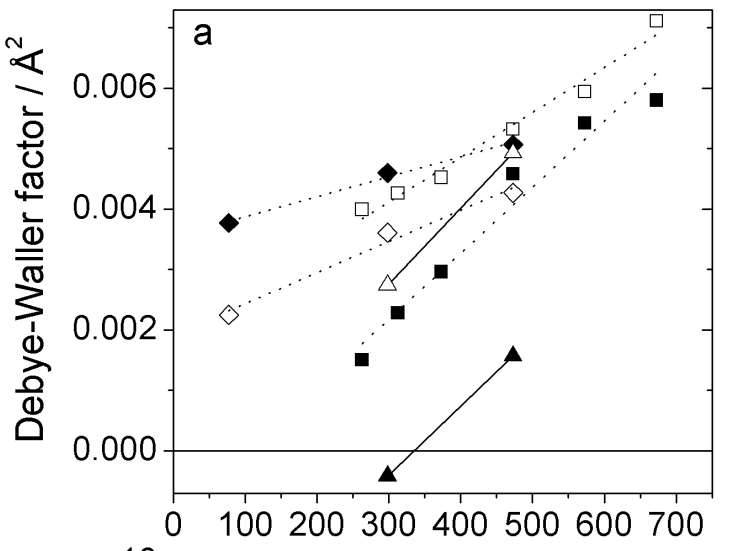

Fig. 3 (a) $\Delta \sigma^{2}$, (b) $E_{0}$ correction, (c) Pt-Pt distance, and (d) third cumulant as function of temperature for $\mathrm{Pt} / \mathrm{Al}_{2} \mathrm{O}_{3}$ and $\mathrm{Pt} / \mathrm{SiO}_{2}$ measured in vacuum. $\mathrm{Pt} / \mathrm{Al}_{2} \mathrm{O}_{3}-79 \mathrm{a}$ $(\diamond / \diamond), \mathrm{Pt} / \mathrm{Al}_{2} \mathrm{O}_{3}-79 \mathrm{~b}(\square / \mathbf{\bullet}), \mathrm{Pt} / \mathrm{SiO}_{2}-57$ $(\triangle / \mathbf{\Delta})$. Without cumulants: open symbols. With higher-order cumulants: filled symbols. Dotted lines are trends. Errors: without cumulants: $50 \%$ in $\Delta \sigma^{2}, 1 \%$ in $R, 2$ $\mathrm{eV}$ in $\Delta E_{0}$, with cumulants: $200 \%$ in $\Delta \sigma^{2}$, $3 \%$ in $R, 4 \mathrm{eV}$ in $\Delta E_{0}, 5 \times 10^{-4} \AA^{3}$ in $C_{3}$.
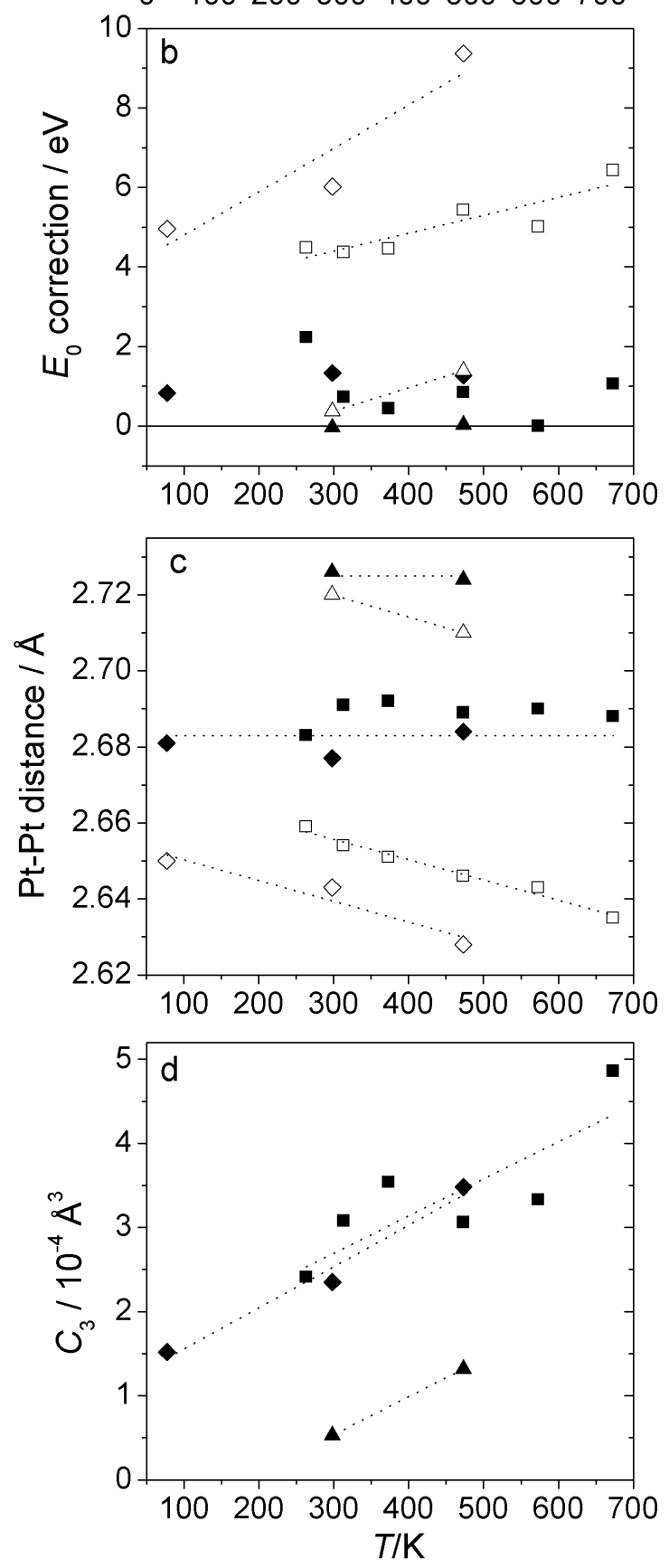


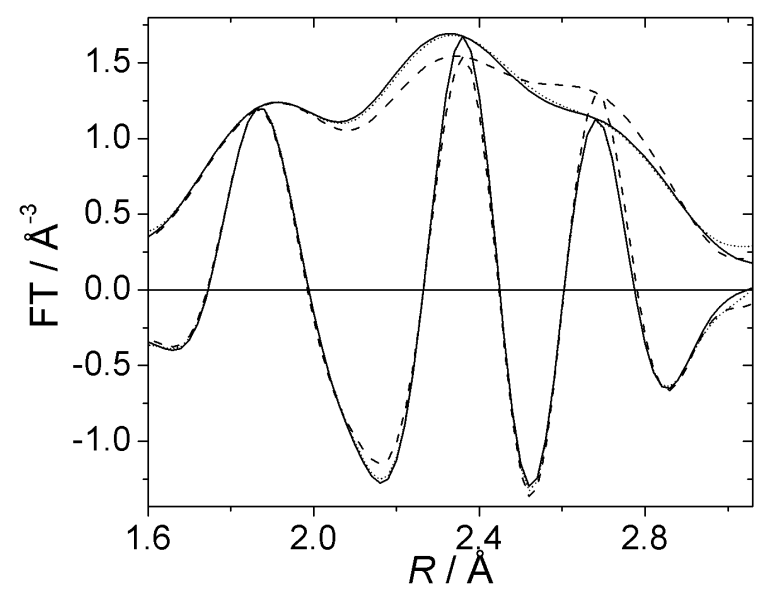

Fig. $4 k^{3}$-weighted Fourier-transform (solid line), best fit without including higher-order cumulants (dashed line), and including higher-order cumulants (dotted line) of $\mathrm{Pt} / \mathrm{Al}_{2} \mathrm{O}_{3}$ 79 at $673 \mathrm{~K}$, in vacuum. ( $R$-space, $k^{3}$ weighted fit, $1.6<R<3.1 \AA, 3.2<k<13 \AA^{-1}$ ). 

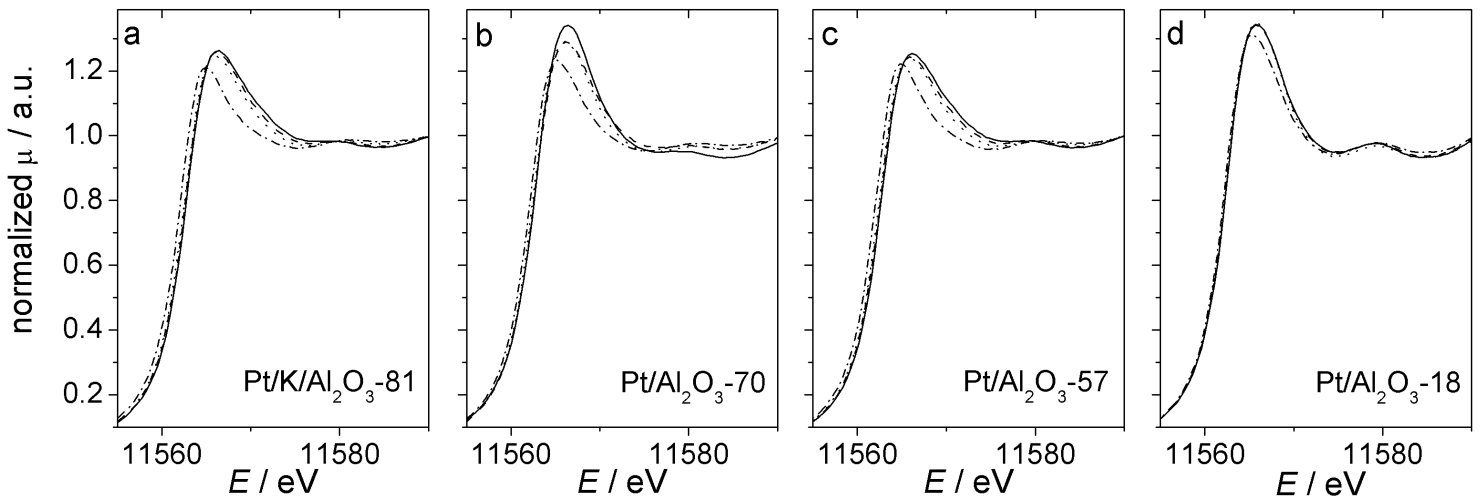

Fig. $5 \mathrm{Pt} \mathrm{L}_{3} \mathrm{XANES}$ in $4 \% \mathrm{H}_{2} / \mathrm{He}$ at 283 (solid), 400 (dashed), 530 (dotted), and $670 \mathrm{~K}$ (dashed-dotted). (a) $\mathrm{Pt} / \mathrm{K} / \mathrm{Al}_{2} \mathrm{O}_{3}-81$, (b) $\mathrm{Pt} / \mathrm{Al}_{2} \mathrm{O}_{3}-70$, (c) $\mathrm{Pt} / \mathrm{Al}_{2} \mathrm{O}_{3}-57$, and (d) $\mathrm{Pt} / \mathrm{Al}_{2} \mathrm{O}_{3^{-}}$ 18. 

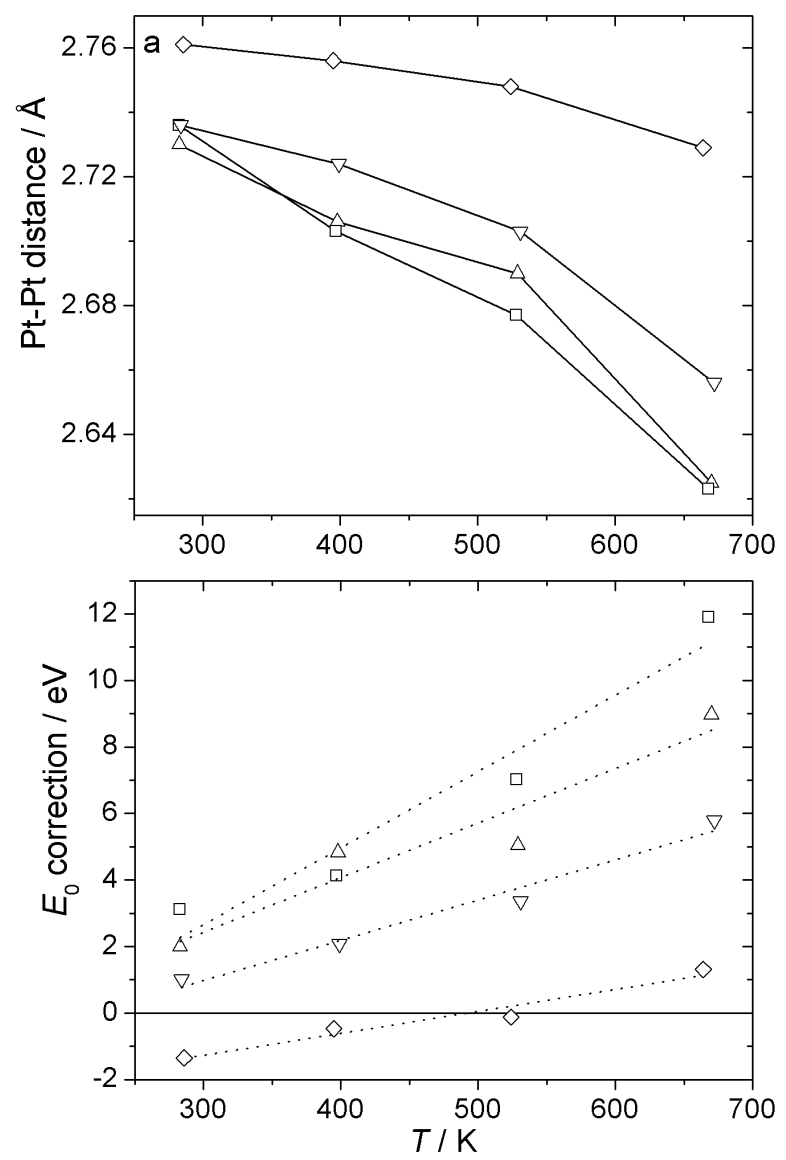

Fig. 6 Fit results of the spectra recorded in hydrogen atmosphere when assuming a symmetric distribution in distances and low disorder of $\mathrm{Pt} / \mathrm{K} / \mathrm{Al}_{2} \mathrm{O}_{3}-81(\triangle), \mathrm{Pt} / \mathrm{Al}_{2} \mathrm{O}_{3}-70$ $(\square), \mathrm{Pt} / \mathrm{Al}_{2} \mathrm{O}_{3}-57(\nabla)$, and $\mathrm{Pt} / \mathrm{Al}_{2} \mathrm{O}_{3}-18(\diamond)$. Dotted lines are trends. (a) Pt-Pt distance and (b) $E_{0}$ correction. Errors: $1 \%$ in $R, 1 \mathrm{eV}$ in $\Delta E_{0}$. 


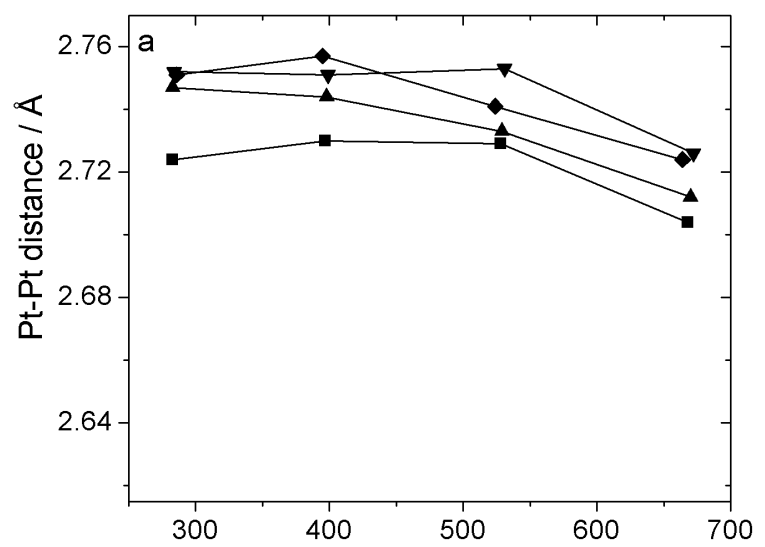

Fig. 7 Fit results of the spectra recorded in hydrogen atmosphere when including higher order cumulants of $\mathrm{Pt} / \mathrm{K} / \mathrm{Al}_{2} \mathrm{O}_{3}$ -

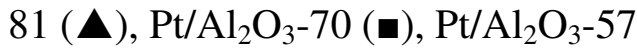
( $\boldsymbol{\nabla}$ ), and $\mathrm{Pt} / \mathrm{Al}_{2} \mathrm{O}_{3}-18$ ( ). (a) Pt-Pt distance, (b) $E_{0}$ correction, (c) third cumulant, and (d) fourth cumulant. Dotted lines are trends. Errors: $1 \%$ in $R$, $2 \mathrm{eV}$ in $\Delta E_{0}, 5 \times 10^{-4} \AA^{3}$ in $C_{3}, 1 \times 10^{-5} \AA^{4}$ in $C_{4}$.
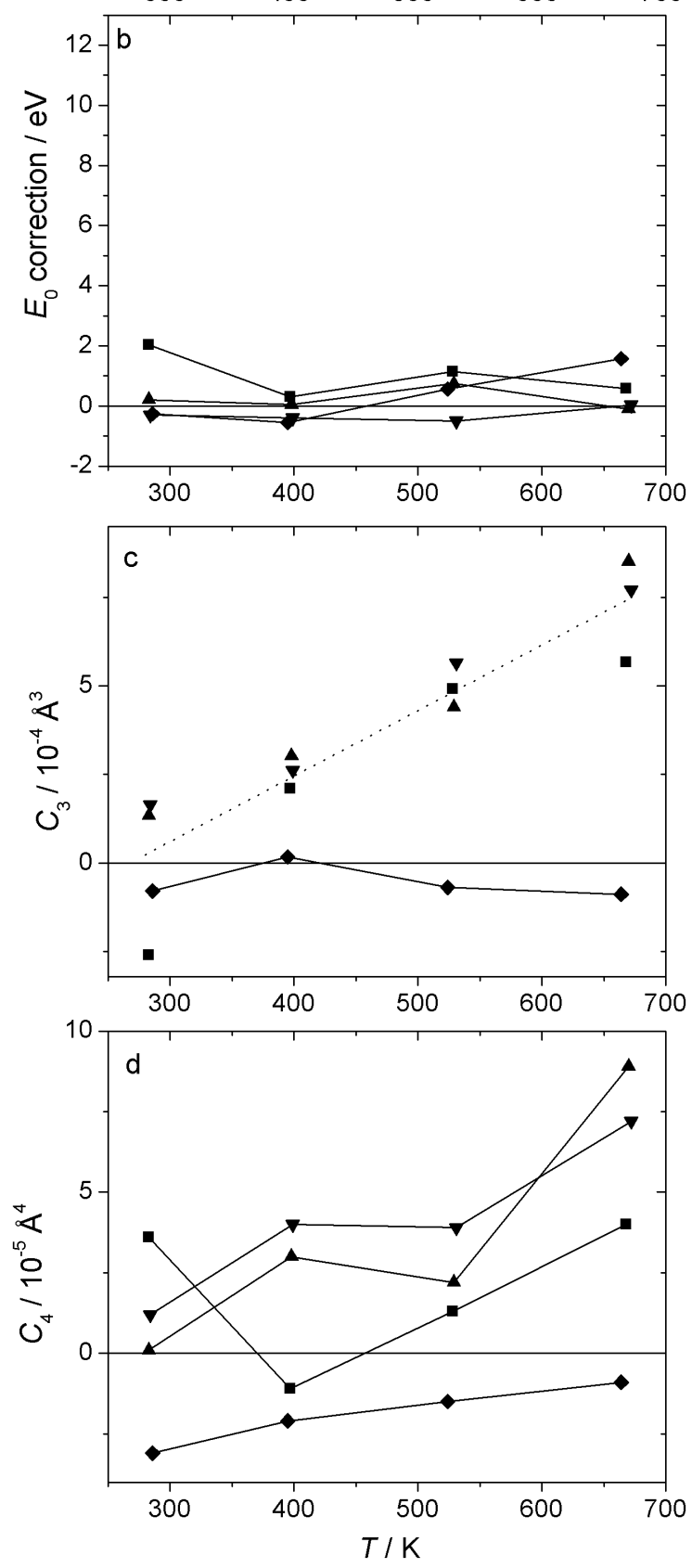
Graphical and textual abstract:

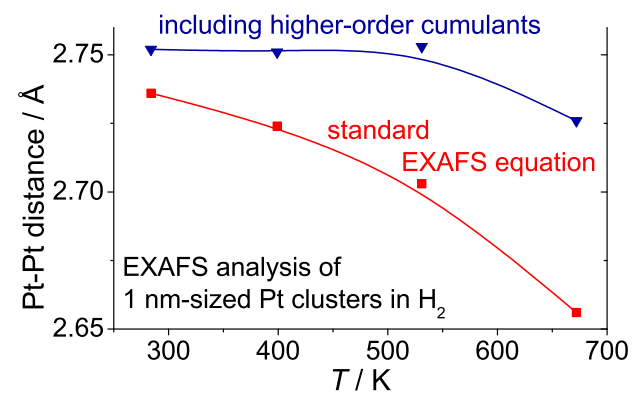

The structural parameters of supported Pt catalysts as found with EXAFS are corrected using the third and fourth cumulant. 